\title{
Perceptions of the dimensions of the fairness of affirmative action: A pilot study
}

\author{
L.P. Vermeulen* \\ Department of Human Resources Management, \\ University of Pretoria, Pretoria 0002, Republic of South Africa \\ leo.vermeulen@up.ac.za \\ M. Coetzee \\ Department of Human Resources Management \\ University of South Africa
}

Received June 2006

\begin{abstract}
The purpose of this study was to identify the dimensions of affirmative action (AA) fairness in order to develop a valid and reliable questionnaire to assess employees' perceptions of the fairness of AA decisions and practices, and to explore the relationship between employees' biographical characteristics and their perceptions of the dimensions of AA fairness. The research sample consisted of 349 participants connected to a large financial institution in South Africa. Principal axis factor analysis with a varimax rotation was performed on the data in order to uncover the different factors that employees perceived to be important for the fair and just management of affirmative action practices. Four factors define AA fairness: namely interactional, procedural (input), procedural (criteria) and distributive justice. One-way MANOVAs and associated ANOVAs revealed that the importance of the justice factors in AA fairness differed significantly across ethnicity and staff category. This study enables a better understanding of the dimensionality of AA fairness. It should ultimately contribute to more effective management of AA in the workplace.
\end{abstract}

*To whom all correspondence should be addressed.

\section{Introduction}

Since its first democratic election on 27 April 1994, attempts to make South Africa a more just society have increased, and topics such as equality and social justice frequently appear at the top of company agendas. The government decided that legislation to guide organisations in promoting justice in the workplace was needed. Hence, three Acts related to affirmative action (AA) were promulgated, namely the Employment Equity Act 55 of 1998, the Promotion of Equality and the Prevention of Unfair Discrimination Act 4 of 2000 and the Preferential Procurement Policy Framework Act 5 of 2000. The intention with these Acts was to govern the promotion of social justice and to eradicate inequalities in the workplace (Bendix, 2001; Employment Equity Report, 2001; Van Wyk, 2002).

In South Africa, no other issue has raised as many concerns about justice as AA (Van Jaarsveld, 2000). For many years, AA has been a battleground for competing values, especially regarding competing concepts of distributive justice. In the USA, after 20 or more years of AA, the government has finally admitted that the process has failed (Van Jaarsveld, 2000). Why? Because AA programmes were not implemented fairly; nor were employees' perceptions of the fairness of these AA programmes managed. When employees regard something as unfair, they tend to reject it; and any further interventions are then doomed to fail (Sheppard, Lewicki \& Minion, 1992). If South Africa wishes to make a success of AA, organisations need to understand how perceptions of AA influence employees' attitudes and behaviour and consequently affect the success of the organisation.

AA is meant to ensure macro justice (justice between groups), but resistance frequently arises because of concerns about micro justice (justice for individuals) (Clayton \& Tangri, 1989). The accusations most frequently levelled at AA are that AA is a form of reverse discrimination (Thomas, 2002); that AA appointees are less competent than some other applicants and lack the necessary skills, and that they are appointed to fill quotas or to window-dress (Van Jaarsveld, 2000); that AA implies inferiority and that it stigmatizes its beneficiaries (Resendez, 2002); and that AA decisions are based on preferential treatment rather than on merit (Elkins, Bozeman \& Phillips, 2003). Swim and Miller (1996) also claim that AA can be read as retribution against White people. Groarke (1990) takes issue with AA because he suggests that it penalizes young White men who were not, as individuals, responsible for historical discrimination. Numerous studies have revealed that opposition to affirmative action is related to people's perceptions of fairness (or a lack of fairness) in their understanding of AA. One important reason for negative attitudes towards AA arises from a perception that organisations are not committed to fairness. In an extensive review of the psychological and behavioural research on AA, the Society for Industrial and Organizational Psychology (SIOP) has indicated that much of the AA debate focuses on the issue of perceived fairness (SIOP, 1996).

South African organisations will continue to be evaluated in terms of how well they meet employment equity targets. This will ensure that the changing nature of society is 
reflected in the composition of every local organisation's workforce. For a programme to be regarded as effective, it needs to comply with both the legal and the fairness requirements. Organisations will thus be under increasing pressure to implement AA programmes that are technically and morally sound - and that can be shown to be so. This is particularly significant if one considers that employees are more inclined to challenge procedures that they regard as unfair than ones they believe to be fair (Cooper \& Robertson, 1995). Many researchers implicitly or explicitly assume that people's attitudes toward AA are driven by fairness judgments. It is therefore consistent with this assumption that they tend to assess perceptions of fairness rather than general attitudes (SIOP, 1996).

\section{Organisational justice}

In an attempt to describe and explain the role of fairness as a consideration in the workplace, a field of study known as organisational justice has emerged. Organisational justice refers to people's perceptions of fairness in organisational settings. People tend to make fairness judgments by looking at the actual decision or the procedures used to reach a decision. Organisational justice can be divided into distributive, procedural and interactional fairness. Figure 1 illustrates the various types of justice and how they relate to one another.

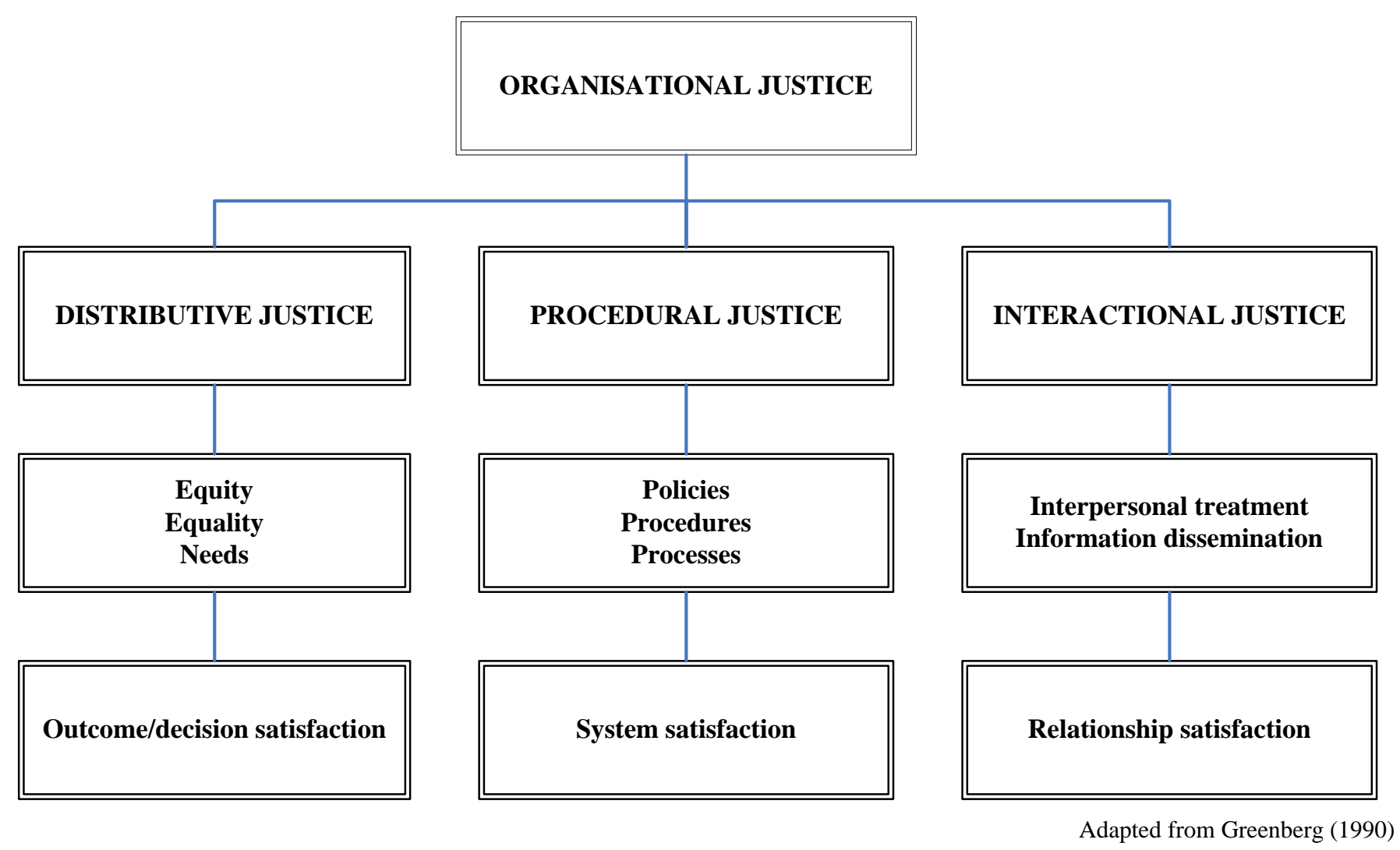

Figure 1: Various types of organisational justice and their interrelatedness

Traditionally, the study of fairness in organisations was dominated by a distributive justice orientation. Folger and Cropanzano (1998) define distributive justice as the perceived fairness of the outcome of a decision. Depending on how outcomes are allocated, distributive justice is determined by using three key justice rules: the equity rule, the equality rule and the need rule (Deutsch, 1985; Gilliland \& Paddock, 2005).

- The equity rule proposes that individuals determine the fairness of the outcomes received by comparing their contributions to the organisation with the inputs of referent others.

- $\quad$ The equality rule implies that individuals have an equal allocation or chance at the outcome, regardless of their contributions.
- The need rule refers to the distribution of rewards or the allocation of outcomes on the basis of the needs of individuals, groups and/or organisational goals set by management.

Gilliland and Paddock (2005) considered the ways in which the three distributive justice rules vary across different human resource (HR) functions and found that equity is a salient principle for most HR decisions. Deutsch (1985) suggested that the rule used in the distribution of allocations depends on the objective of the allocator. In the case of AA, management is likely to allocate AA outcomes according to the distributive rule of need to ensure that the organisation complies with government policies and goals.

Some researchers, such as Leventhal (1976) and Thibaut and Walker (1975), have expanded the distributive justice orientation to include some consideration of the processes 
that organisations use to determine the outcomes- that is, adopting a procedural justice orientation. This dimension of organisational justice refers to perceptions of the fairness of the processes that culminate in an event, decision or action. It is related to the means, methods and mechanisms used to determine outcomes (Folger \& Cropanzano, 1998; Harris, 2000; Sheppard et al., 1992). According to Leventhal, Karuza and Fry (1980), Brockner and Wiesenfeld (1996) and Gilliland and Paddock (2005), procedures are perceived as fair if decisions are made consistently, without selfinterest and on the basis of accurate information; if there are opportunities to correct the decision and to appeal the outcome arrived at using the procedures; if the decisions represent the interests of all the parties concerned, follow moral and ethical standards and if they set ground-rules (criteria) for evaluating and decision-making.

Further research has focused on people's feelings about unfair treatment. It has revealed a third dimension of organisational justice, which was named interactional justice. This type of justice includes two subtypes, namely interpersonal and informational fairness (Hemingway \& Conte, 2003; Gilliland \& Paddock, 2005). Interpersonal fairness refers to people's sensitivity to the quality of the interpersonal treatment that they think they receive and the extent to which the decision-maker shows respect for the rights of the parties affected by the decision (Greenberg, 1996; Hemingway \& Conte, 2003). Informational fairness includes providing adequate information and explaining the procedures followed in implementing organisational policies (Colquitt, 2001; Gilliland \& Paddock, 2005).

As the distinction between distributive, procedural and interactional justice has already been empirically established, the stage was set for researchers to consider how these varieties of justice relate to various organisational variables such as turnover, commitment, trust and supervisor/subordinate relationships. Folger and Cropanzano (1998) indicate that injustice may result in negative consequences, for example, reduced job performance (Greenberg, 1988; Pfeffer \& Langton, 1993), reduced cooperation with co-workers (Pfeffer \& Langton, 1993), lower work quality (Cowherd \& Levine, 1992), stress (Zohar, 1995), and even theft (Greenberg, 1990). Once managers understand how perceptions of organisational justice are related to these variables, organisations can attempt to manage employees' perceptions of fairness across human resources management decisions (Gilliland \& Paddock, 2005).

Several studies on organisational justice in South Africa have examined the fairness of various organisational practices, such as the right to equality of treatment in selection and recruitment (Van Niekerk, 1996); organisational justice in personnel selection (De Jong \& Visser, 2000a; De Jong \& Visser, 2000b; Visser \& De Jong, 2001); the relationship between organisational justice, transactional leadership and trust (Krafft, Engelbrecht \& Theron, 2004); and procedural justice in the retrenchment of managers (Vermeulen, 2005). However, no South African studies could be found with regard to the importance of organisational justice principles in employees' perceptions of the fairness of AA programmes.
With due consideration of the forementioned, the following research questions were asked as a point of departure in this study:

\section{- What constitutes AA fairness?}

- Do biographical characteristics of employees' relate to their perceptions of the fairness of AA?

Based on these questions, the objectives of this study were the following:

to develop a valid and reliable instrument to measure the perceptions of employees with regard to the fairness of AA decisions and practices; and to explore the relationship between gender, ethnicity, staff category and the perceptions held by employees with regard to AA fairness.

\section{Methodology}

\section{Research approach}

A comprehensive literature study was performed to answer the above research questions and to reach the research objectives. The purpose of the literature study was to identify fairness principles and to outline AA practices that could influence employees' perceptions regarding fairness. Once the literature study had been completed, a measuring instrument was developed to survey employees' perceptions with regard to the organisational justice factors that influence the fairness/unfairness of AA.

\section{Measurement}

Because there was no established questionnaire on AA fairness, the researchers developed their own questionnaire to collect the data. For the purposes of this study, the questionnaire is referred to as the AA Fairness Questionnaire (AAFQ). The AAFQ consists of Section A (Biographic information), and Section B (Items related to the fairness of AA). Section B attempts to determine what behaviour, decisions and practices are perceived to be important in judging the fairness of AA. The original 40 items included in Section B parallel the elements of organisational justice and the principles of fairness mentioned by Colquitt (2001), Folger and Cropanzano (1998), Greenberg (1990), Kaufman (1982), Konovsky and Brockner (1993), Leventhal (1976), and Thibaut and Walker (1975). The rules and principles of distributive, procedural and interactional justice were used as a basis to compile the item pool for the questionnaire.

The respondents were asked to reflect on their perceptions using a six-point scale, where only the extremes of the scale were defined. Even number response categories were used in order to eliminate the central tendency effect and all the items were anchored by 'Not at all' (1) on the one hand, and 'To a very great extent' (6) on the other hand. Schepers (1992, cited in Petkoon \& Roodt, 2004), argues that the quality of the results achieved using an equal-interval scale declines when more than two of the points on the scale are anchored. 


\section{The sample}

The sample consisted of employees from a leading bank in South Africa. A disproportionate, stratified sampling method was used. In this study, the subgroups were determined according to ethnicity, gender and staff category. With regard to ethnicity, employees from the non-White population groups (Black, Coloured and Asian respondents) were treated as a single component in terms of ethnicity. With regard to the staff category, employees from top management, middle management and the supervisory level were treated as a single component. Once this process had been completed, a list of employees was drawn randomly from each group, and a total of 1720 employees were targeted. The questionnaires were distributed to each member of the sample, accompanied by a covering letter stressing the confidentiality of the information obtained.
A total of 392 completed questionnaires were returned, of which 349 were usable, resulting in a response rate of 20,3 per cent. No information is available as to why only 20,3 per cent of the employees responded. No evidence of bias in the sample distribution for ethnicity and gender could be detected; however, the observed response frequency in the staff categories differed significantly from the expected distribution. Sixty-four more managers and sixty-five less clerical staff responded then expected.

Table 1 depicts the sampling frame, the number of usable responses received for each demographic group and the ChiSquare Goodness-of-Fit results for the observed and expected response distributions. Table 2 indicates the distribution of the responses by demographic group.

Table 1: Sampling frame and responses received for each demographic group

\begin{tabular}{|c|c|c|c|c|c|}
\hline \multirow[t]{2}{*}{ Demographic group } & \multicolumn{2}{|c|}{ Sample frame } & \multicolumn{2}{|c|}{ Responses received } & \multirow[t]{2}{*}{ Goodness-of-fit } \\
\hline & Frequency & $\%$ & Frequency & $\%$ & \\
\hline \multicolumn{6}{|l|}{ Ethnicity } \\
\hline Black & 668 & 40 & 128 & 36,7 & \multirow{2}{*}{$\begin{array}{l}\chi^{2}=1,606 \\
\mathrm{df}=1 \\
\operatorname{sig}=0,205\end{array}$} \\
\hline White & 1032 & 60 & 221 & 63,3 & \\
\hline \multicolumn{6}{|l|}{ Gender } \\
\hline Men & 585 & 34 & 120 & 34,4 & \multirow{2}{*}{$\begin{array}{l}\chi^{2}=0,026 \\
\mathrm{df}=1 \\
\operatorname{sig}=0,880\end{array}$} \\
\hline Women & 1135 & 66 & 229 & 65,6 & \\
\hline \multicolumn{6}{|l|}{ Staff category } \\
\hline Management & 498 & 29 & 168 & 48,0 & \multirow{2}{*}{$\begin{array}{l}\chi^{2}=54,672 \\
\mathrm{df}=1 \\
\text { sig }=0,01\end{array}$} \\
\hline Clerical & 1222 & 71 & 181 & 52,0 & \\
\hline TOTAL & 1720 & & 349 & & \\
\hline
\end{tabular}

Table 2: Distribution of the responses by demographic group

\begin{tabular}{|c|c|c|c|c|c|c|c|}
\hline \multirow[b]{2}{*}{ Responses } & \multicolumn{3}{|c|}{ Black } & \multicolumn{3}{|c|}{ White } & \multirow[b]{2}{*}{ Total } \\
\hline & Male & & Female & Male & & Female & \\
\hline Management & 12 & & 11 & 71 & & 74 & 168 \\
\hline Clerical staff & 28 & & 77 & 9 & & 67 & 181 \\
\hline \multirow[t]{2}{*}{ Total } & 40 & & 88 & 80 & & 141 & 349 \\
\hline & & 128 & & & 221 & & \\
\hline
\end{tabular}

The sample consisted of $36,7 \%$ Black and 63,3\% White respondents, with a gender ratio of $65,6 \%$ females to $34,4 \%$ males. The clerical staff made up $52,9 \%$ of the sample and the management staff represented $48,1 \%$. The respondents' mean length of service in the bank was 10,4 years (SD= 8,443). Their ages ranged between 19 and 62 years, with a mean age of 36,9 years $(S D=10,358)$. A total of $52 \%$ of the respondents had a post-matriculation qualification and the majority (65 6\%) were married.

\section{Statistical analysis}

Descriptive, associational and comparative statistics were used to analyse the data. The SPSS for Windows Statistical Package, Release 11 and 12, was applied for all the statistical procedures.
Descriptive statistics were included in order to summarise the data, to describe the sample and to calculate the mean, standard deviation, skewness and kurtosis of the sample scores on the dependent variables (AA fairness). The ChiSquare Goodness-of-Fit Test was used to see whether the observed frequency distribution of the respondents could reasonably have come from the expected sample frame distribution. To assess compliance with the requirements for the distribution of scores, the assumption of normality, Bartlett's test of sphericity, the Kaiser-Meyer-Olkin measure of sampling adequacy and Levene's test for the equality of variances were examined, as suggested by Hair, Anderson, Tatham and Black (1998).

To explore and examine the internal structure and factor validity of the AAFQ, principal factor analysis was used. 
The internal consistency of the AAFQ was assessed by calculating the Cronbach Alpha coefficient for each scale.

One-way multivariate analyses of variance (MANOVAs) were used to explore the relationship between the biographical variables of the respondents and their perceptions of AA fairness. Analyses of variance (ANOVAs) were used to measure any statistically significant differences between the mean scores of the different subgroups in the sample (Hair et al., 1998). The partial eta square $\left(\eta^{2}\right)$ was calculated to determine the effect sizes or strength of association between the biographical variables and the perceptions of AA fairness (Cohen, 1988). Effect size in this context does not refer to cause and effect relationships between variables, but provides a value that quantifies the practical significance of findings, as indicated by Rosenthal, Rosnow and Rubin (2000).

\section{Results}

\section{Principal factor analysis}

In order to determine which variables cluster together, the intercorrelation matrix of the 40 items was subjected to a principal factor analysis and rotated by means of the varimax rotation to identify the substructures in the data matrix. In order to enhance the discriminant validity of the AAFQ, items that cross-loaded on more than one factor and items with factor loadings less then 0,40 were omitted. Once 11 items had been excluded, another factor analysis was done. The Kaiser-Meyer-Olkin (KMO) measure of sampling adequacy and Bartlett's test of sphericity produced satisfactory results. The KMO value $(0,933)$ was greater than 0,7 . This meant that the data set was likely to factor well. Bartlett's test of sphericity confirmed $\left[\chi^{2}(406)=\right.$ $5374,294, \mathrm{p}<0,001]$ that the properties of the correlation matrix of the item scores were suitable for factor analysis. Based on Kaiser's criterion (eigenvalues greater then one) and the Scree plot, four factors were postulated which explained $57,2 \%$ of the variance in the factor space. All the items had loadings higher than 0,433 and the four factors were well determined. A description of the items used in the second factor analysis is set out in Appendix A. The rotated factor matrix of the solution, the eigenvalues and percentage variance explained are set out in Table 3.

After studying the contents of the items defining each factor, the following descriptive labels were assigned to the factors:

\section{- $\quad$ Factor 1: Interactional justice}

This factor focuses primarily on how employees are treated, informed and considered in the management of AA practices. The elements of this factor include recognising the value and abilities of employees from designated groups, guiding employees from designated groups to build realistic career expectations, keeping employees informed about employment AA issues, training supervisors to manage diversity, making complete and accurate records available about any decisions that were based on employment equity provisions and accommodating diverse cultures.

\section{- $\quad$ Factor 2: Procedural justice - input}

This factor refers to the opportunities employees have to influence the final decision or outcome of AA. Management regard all employees' career advancements as equally important, allow employees to appeal, afford employees the opportunity to influence a selection decision, use joint decision-making, provide mechanisms to protect employees against discrimination, apply rules and procedures strictly and consistently, and adjust systems to integrate AA employees.

\section{- $\quad$ Factor 3: Procedural justice - criteria/standards}

This factor also refers to the procedures but focuses on the criteria or standards used in making AA decisions. The elements of this factor include applying selection criteria consistently, using accurate performance data to evaluate an employee, applying the same performance standards to all employees, using predetermined job-related selection criteria, using more than one person to appraise an employee's performance, and taking disciplinary action strictly and consistently.

\section{- $\quad$ Factor 4: Distributive justice}

This factor refers to the allocation of AA outcomes. It includes issues such as being seen to grant Black employees token positions, training AA employees to replace current job incumbents, paying unrealistically high salaries to AA appointees, appointing or promoting less qualified employees, recruiting AA employees by means of special provisions in advertisements, making selection decisions on the basis of the employment equity plan and workforce profile, focusing on the development and advancement of AA employees and making selection decisions on the basis of criteria such as ethnicity, gender and disability.

The factor analysis resulted in four-factor measurement model of which the constructs/dimensions seem to be congruent with existing organisational fairness theories. The results indicated that the respondents' perceptions about the fairness of AA are related to the way employees were informed and treated during the $\mathrm{AA}$ intervention $(\mathrm{F} 1=$ interactional justice); the procedures applied in making AA decisions (F2 \& F3 = procedural justice); and the allocation of AA outcomes (F4 = distributive justice).

\section{Item analysis and reliability}

Next, the items of the four factors were subjected to item analysis. The mean, standard deviation, skewness, kurtosis and coefficient alpha were computed for each of the factors. The item and descriptive statistics are reported in Table 4. The factor means varied from 23,219 to 31,591 and the standard deviations from 7,139 to 8,215 . The internal consistency reliability index for the four factors ranged between 0,806 and 0,884. The scores of the sample were approximately normally distributed. The assumption of normality requires that the key statistics (skewness and kurtosis) be less than 2,5 times its standard error (Morgan \& Griego, 1998). The results confirm that the AAFQ has acceptable psychometric properties. 
Table 3: Factor loadings, eigenvalues and percentage variance for the principal factor extraction and varimax rotation of the AAFQ items

\begin{tabular}{|c|c|c|c|c|}
\hline Items & Factor 1 & Factor 2 & Factor 3 & Factor 4 \\
\hline Recognising the value of AA employees & 0,727 & & & \\
\hline Acknowledging that employees from designated groups are capable & 0,644 & & & \\
\hline Guiding AA to create realistic career expectations & 0,590 & & & \\
\hline Informing employees about AA policy & 0,572 & & & \\
\hline Training supervisors to manage diversity & 0,519 & & & \\
\hline Accommodating AA culture when socialising & 0,507 & & & \\
\hline Making accurate and complete records available & 0,491 & & & \\
\hline Informing employees of the AA implications for careers & 0,488 & & & \\
\hline Regarding all employees' career advancement as equally important & & 0,681 & & \\
\hline Enabling employees to appeal & & 0,677 & & \\
\hline Giving all applicants an equal chance to influence the selection decision & & 0,614 & & \\
\hline Joint decision-making by all interested parties & & 0,550 & & \\
\hline Provide mechanisms to protect against discrimination & & 0,520 & & \\
\hline Applying rules/procedures strictly and consistently & & 0,491 & & \\
\hline Adjusting systems to integrate AA employees & & 0,435 & & \\
\hline Applying selection criteria consistently & & & 0,742 & \\
\hline Using accurate performance data for evaluation & & & 0,702 & \\
\hline Using the same performance standards for all & & & 0,681 & \\
\hline Using predetermined, job-related selection criteria & & & 0,601 & \\
\hline Using more than one performance appraiser & & & 0,503 & \\
\hline Applying disciplinary action strictly and consistently & & & 0,447 & \\
\hline Giving black managers token positions & & & & 0,682 \\
\hline Training employees from designated groups to replace job incumbents & & & & 0,668 \\
\hline Paying unrealistically high salaries for managers from designated groups & & & & 0,653 \\
\hline Appointing/promoting less qualified people from designated groups & & & & 0,650 \\
\hline $\begin{array}{l}\text { Targeting people from designated groups through provisions in } \\
\text { advertisements }\end{array}$ & & & & 0,504 \\
\hline Using an AA plan and workforce profile to appoint & & & & 0,481 \\
\hline $\begin{array}{l}\text { Focusing on the development/advancement of employees from designated } \\
\text { groups }\end{array}$ & & & & 0,464 \\
\hline Using criteria (ethnicity, gender) in appointment decisions. & & & & 0,434 \\
\hline Eigenvalue & 10,904 & 3,287 & 1,214 & 1,161 \\
\hline Percentage variance & 37,601 & 11,335 & 4,187 & 4,003 \\
\hline
\end{tabular}

Table 4: Descriptive statistics and reliability of the AAFQ factors

\begin{tabular}{l|c|c|c|c|c|c|c|c}
\hline \multicolumn{1}{c|}{ Fairness factors } & $\begin{array}{c}\text { Total } \\
\text { items }\end{array}$ & $\begin{array}{c}\text { Mean } \\
\text { score }\end{array}$ & $\begin{array}{c}\text { Standard } \\
\text { deviation }\end{array}$ & \multicolumn{2}{|c|}{ Skewness } & \multicolumn{2}{c}{ Kurtosis } & Alpha \\
\hline & & & & Sk & S/error & \multicolumn{2}{c}{ Ku } & S/error \\
\hline Interactional & 8 & 31,591 & 8,215 & $-0,198$ & 0,131 & $-0,222$ & 0,260 & 0,8844 \\
\hline Procedural (input) & 7 & 26,469 & 8,023 & $-0,006$ & 0,131 & $-0,717$ & 0,260 & 0,8642 \\
\hline Procedural (criteria) & 6 & 23,249 & 7,139 & $-0,147$ & 0,131 & $-0,711$ & 0,260 & 0,8796 \\
\hline Distributive & 8 & 31,303 & 7,821 & $-0,194$ & 0,131 & 0,029 & 0,260 & 0,8064 \\
\hline
\end{tabular}




\section{Analysis of variance}

In order to explore whether ethnicity, gender and staff category are related to employees' perceptions about the fairness of AA, three one-way MANOVAs and ANOVAs were performed. To adjust for unequal numbers of scores (unequal $\boldsymbol{n}$ ) the Type 1 method was used to calculate the sum of the squares for each effect (Tabachnick \& Fidell, 2001). The means, standard deviations and Levene's test for the equality of variance were also calculated across all biographical subgroups for each of the factors. The results are reported in Tables 5 to 8 .

One-way multivariate analyses of variance (MANOVAs) were performed in order to ascertain whether there are statistically significant differences between the means of the subgroups of the sample in respect of gender, ethnicity and staff category as far as the AA fairness factors' scores are concerned. Table 6 provides a summarized comparison of the vectors of the mean scores of the biographical subgroups, using Hotelling's Trace statistics.

From Table 6, it is apparent that in this sample there were no statistically significant differences $(p=0,558)$ between the vectors of the mean scores of men and women with regard to their perceptions of AA fairness (Hotelling's $\mathrm{T}^{2}=0,009$; $\left.F(4,334)=0,750, p=0,558 ; \eta^{2}=0,009\right)$. However, differences were found for the different ethnic groups and staff categories. Hotelling's $\mathrm{T}^{2}$ of 0,223 with associated $\mathrm{F}$ $(4,334)=19,139, p=0,001$ and $\eta^{2}=0,182$ was statistically significant for ethnicity. Hotelling's $\mathrm{T}^{2}$ of 0,089 with $\mathrm{F}$ $(4,334)=7,681, p=0,001$ and $\eta^{2}=0,082$ was also statistically significant for the staff category.

The differences in the mean scores of the importance of the justice factors in AA fairness were further analysed across ethnicity and staff category, using ANOVAs and Cohen's criteria of practical significance. According to Cohen (1988), the effect size is 'large' when $\eta^{2}>0,15$; 'medium' when $\eta^{2}=0,06$ to 0,14 ; and 'small' when $\eta^{2}=0,01$ to 0,03 . The results of the ANOVAs for the different ethnic groups are set out in Table 7 and the results for the different staff categories in Table 8.

As can be seen in Table 7, there were statistically significant differences $(\mathrm{p}<0,05)$ between Black respondents' and White respondents' perceptions with regard to the importance of the justice factors in AA fairness. White respondents in this sample seemed to regard interactional, procedural (input and criteria) and distributive justice as more important for AA fairness than the Black respondents did. However, the differences between Black and White respondents are of practical significance only with regard to distributive justice. The strength of the association between ethnicity and distributive justice was $\eta^{2}=0,17$ (large effect). The difference in mean scores, $\mathrm{F}(1,348)=0,574, \mathrm{p}<0,001$, indicated that the outcomes of AA decisions strongly influence White respondents' perceptions ( $\bar{X}=33,755)$ about the fairness of AA. Black respondents, on the other hand, regarded the outcomes of AA decisions as less important in influencing employee's perceptions $(\bar{X}=27,069)$ about the fairness of AA.

According to Table 8, the mean scores of the managerial and clerical employees in this sample differed significantly $(\mathrm{p}<0.05)$ with regard to interactional, procedural (criteria) and distributive justice. The effect size of the difference for interactional and procedural (criteria) justice was small $\left(\eta^{2}<0,03\right)$. A significant difference $F(I, 348)=0,571$, $\mathrm{p}<0,001,\left(\eta^{2}=0,07\right.$,medium effect $)$ was noted between the mean scores of the managers ( $\bar{X}=32,541$ ) and the clerical staff $(\bar{X}=30,709)$ in respect of the perceived importance they attached to distributive justice. It seems that managers believe that decisions such as giving AA employees token positions, paying unrealistically high salaries to AA managers, and so on are more important in influencing perceptions about the fairness of AA than clerical staff do.

\section{Discussion}

The objectives of this study were to develop a valid and reliable instrument to measure the perceptions of employees with regard to the fairness of AA decisions and practices; and to explore the relationship between gender, ethnicity, staff category and the perceptions held by employees with regard to AA fairness.

The findings of the present study can be seen as the first step toward defining the factors or dimensions employees perceive to be important in judging the fairness of their organisations' AA programmes. Principal factor analysis yielded four well-determined factors that are perceived to underscore just and fair AA practices. These factors are related to the way employees are considered, informed and treated during the application of AA interventions (interactional justice); the use of the input of employees and the application of criteria and standards when making AA decisions (procedural justice); and the allocation of 'functional or dysfunctional' AA outcomes (distributive justice). The four dimensions are closely linked to the organisational justice models presented or cited by various authors (Colquitt, 2001; Deutsch, 1985; Greenberg, 1990; Sheppard et al., 1992; Gilliland \& Paddock, 2005).

Reliability analyses confirmed sufficient internal consistency of the factors. The reliabilities of Factors 1, 2, 3 and 4, according to Cronbach's coefficient alpha, were $0,884,0,864,0,879$ and 0,806 respectively. The alpha coefficient surpassed the minimum level of 0,70 recommended by Morgan and Griego (1998). The results of the factor analysis and reliability indices provided support for the psychometric adequacy of the AAFQ.

To explore the relationship between the importance of the AA fairness factors and gender, ethnicity and staff category, a series of one-way MANOVAs and ANOVAs were performed. 
Table 5: Means and standard deviations of the AA fairness scores across the biographical subgroups

\begin{tabular}{|c|c|c|c|c|c|c|c|c|c|}
\hline \multicolumn{2}{|c|}{$\begin{array}{l}\text { Fairness factors/ } \\
\text { Biographical }\end{array}$} & \multicolumn{2}{|c|}{ Interactional } & \multicolumn{2}{|c|}{ Procedural (input) } & \multicolumn{2}{|c|}{ Procedural (criteria) } & \multicolumn{2}{|c|}{ Distributive } \\
\hline & $\mathbf{N}$ & Mean & SD & Mean & SD & Mean & SD & Mean & SD \\
\hline \multicolumn{10}{|l|}{ Gender } \\
\hline Male & 120 & 30,946 & 8,316 & 25,773 & 7,802 & 23,088 & 7,023 & 31,427 & 8,600 \\
\hline Female & 229 & 31,929 & 8,160 & 26,834 & 8,129 & 23,334 & 7,213 & 31,239 & 7,400 \\
\hline \multicolumn{10}{|l|}{ Ethnicity } \\
\hline Black & 128 & 29,950 & 9,564 & 25,345 & 8,208 & 21,787 & 7,125 & 27,070 & 7,094 \\
\hline White & 221 & 32,542 & 7,175 & 27,120 & 7,859 & 24,097 & 6,972 & 33,755 & 7,159 \\
\hline \multicolumn{10}{|l|}{ Staff category } \\
\hline Management & 168 & 32,541 & 7,495 & 26,914 & 7,585 & 24,173 & 6,945 & 33,442 & 7,490 \\
\hline Clerical & 181 & 30,709 & 8,759 & 26,056 & 8,408 & 22,392 & 7,229 & 29,319 & 7,615 \\
\hline
\end{tabular}

Table 6: MANOVAs: Summary of differences in the vectors of the means of the biographical subgroups for the four AA fairness factors

\begin{tabular}{l|c|c|c|c|c}
\hline Biographical & Value & F & df & p & $\eta^{2}$ \\
\hline Gender & 0,009 & 0,750 & 4,334 & 0,558 & 0,009 \\
\hline Ethnicity & 0,223 & 19,139 & 4,334 & 0,001 & 0,182 \\
\hline Staff category & 0,089 & 7,681 & 4,334 & 0,001 & 0,082 \\
\hline
\end{tabular}

Table 7: ANOVA: Differences in the importance of the dimensions of AA fairness based on ethnicity

\begin{tabular}{|c|c|c|c|c|c|c|c|c|}
\hline \multirow[t]{2}{*}{ Fairness factors } & \multicolumn{2}{|c|}{$\begin{array}{c}\text { Levene's test of } \\
\text { equality of error } \\
\text { variance }\end{array}$} & \multicolumn{6}{|c|}{ Type 1 test of between-subject effects } \\
\hline & $\mathbf{F}$ & $\mathbf{p}$ & ss & df & ms & $\mathbf{F}$ & $\mathbf{p}$ & $\eta^{2}$ \\
\hline Interactional & 15,113 & 0,001 & 544,585 & 1 & 544,585 & 8,237 & 0,004 & 0,023 \\
\hline Procedural (input) & 0,001 & 0,971 & 255,199 & 1 & 255,199 & 3,999 & 0,046 & 0,011 \\
\hline Procedural (criteria) & 0,031 & 0,861 & 432,425 & 1 & 432,425 & 8,671 & 0,003 & 0,024 \\
\hline Distributive & 0,316 & 0,574 & 3622,989 & 1 & 3622,989 & 71,164 & 0,001 & 0,170 \\
\hline
\end{tabular}

Table 8: ANOVA: Differences in the importance of the dimensions of AA fairness based on staff category

\begin{tabular}{l|c|c|c|c|c|c|c|c}
\hline \multicolumn{1}{c|}{ Fairness factors } & \multicolumn{2}{c|}{$\begin{array}{c}\text { Levene's test of } \\
\text { equality of error } \\
\text { variance }\end{array}$} & \multicolumn{1}{c|}{ Type 1 test of between - subjects effects } \\
& F & p & ss & df & ms & \multicolumn{1}{|c}{ F } & p & \multicolumn{1}{|c}{$\eta^{2}$} \\
\hline Interactional & 4,061 & 0,045 & 292,397 & 1 & 292,397 & 4,375 & 0,037 & 0,012 \\
\hline Procedural (input) & 1,226 & 0,269 & 64,086 & 1 & 64,086 & 0,996 & 0,319 & 0,003 \\
\hline Procedural (criteria) & 0,038 & 0,846 & 276,406 & 1 & 276,406 & 5,493 & 0,020 & 0,016 \\
\hline Distributive & 0,321 & 0,571 & 1481,253 & 1 & 1481,253 & 25,949 & 0,001 & 0,070 \\
\hline
\end{tabular}

In this sample, there were no statistically significant differences $(p>0,05)$ between the vectors of the mean scores of men and women with regard to their perceptions of the importance of the AA fairness factors. The expectation was that men would perceive distributive justice and women interactional justice as more important for AA fairness. This line of thinking was parallel to the views of Deaux (1976) and Tata (2000) that men and women differ in their interpersonal orientation, style and goals. Men are more concerned with tasks and status, whereas women are more oriented towards interpersonal aspects. The fact that in this study no statistically significant differences were found can possibly be explained by the findings of Watson and Allen (1989) and Adler (1994), which suggested that gender differences might be dissipating in the contemporary workplace.

Regarding the relationship between the importance of the AA fairness factors and ethnicity, statistically significant differences $(p<0,05)$ were found between the vectors of the mean scores of Blacks and Whites. The mean scores of the White respondents were significantly higher than the mean scores of the Black respondents in respect of interactional, procedural (input and criteria) and distributive justice. Although the F statistics were shown to be significant, only the strength of association between ethnicity and distributive justice was of practical significance $\left(\eta^{2}>0,15\right)$. The actual outcomes of AA decisions were strongly related to White 
respondents' perceptions about the fairness of AA. Black respondents, on the other hand, seemed less concerned about the allocation of outcomes when forming their perceptions of the fairness of AA.

These findings indirectly substantiate those of Janse van Rensburg and Roodt (2005:60), who indicated that, in comparison with Black employees, White 'employees were the least positive in terms of their perceptions of employment equity'. These results can be explained in terms of the self-interest or instrumental model of Thibaut and Walker (1975). This perspective assumes an egotistical view of human nature, according to which employees value and accept outcomes that benefit them (functional outcomes); or resent and reject outcomes that are perceived as unfavourable (dysfunctional outcomes). According to Tata (2000:262), 'such inconsistencies in perceptions can be attributed to the use of different principles of justice'. Fairness is thus in the eye of the beholder. Most AA decisions favour Black employees and it is possible that they are therefore unlikely to question the fairness of AA outcomes. The judgement of the fairness of AA is clearly affected by the implications of AA for the respondent's selfinterest.

The importance of the AA fairness factors yielded a statistically significant relationship with the staff category. The mean scores of managerial and clerical employees differed significantly $(\mathrm{p}<0.05)$ with regard to interactional, procedural (criteria) and distributive justice. Due to a lack of strength of association $\left(\eta^{2}<0,03\right)$, the relationship between staff categories and the importance of interactional and procedural (criteria) justice was negligible. However, a significant difference, with a medium effect size $\left(\eta^{2}=0,07\right)$, existed between the mean scores of managers and clerical staff in respect of their perceptions of the importance of distributive justice. It seems that the managers in the present sample regarded AA outcomes as more important in influencing perceptions about the fairness of AA than clerical staff did.

There are two possible reasons for these findings. The first reason for why managers and clerical staff may have different fairness perceptions is that they have different values and sources of information (Joy \& Witt, 1992). According to Tata (2000), information asymmetries between management and subordinates can influence their respective perceptions of justice. Managers, for example, are likely to focus on the strategy for administering AA as an important goal of social justice and the need for management to comply with the provisions of the Employment Equity Act 55 of 1998 and the Promotion of Equality and the Prevention of Unfair Discrimination Act 4 of 2000. By contrast, subordinates are likely to focus on their knowledge of the implications and long-term effects of AA for them and other co-workers in the organisation. As Tyler (1989:837) points out, 'people expect an organization to use neutral decision-making procedures enacted by trustworthy authorities so that, over time, all group members will benefit fairly from being members of the group'.

The second reason is related to Greenberg's (1990) view that managers are responsible for maintaining fairness in the workplace to attain organisational objectives. He argues that for managers to be effective, they must behave fairly and must convince others of their fairness. It is thus possible that the managers in this sample perceived the AA outcomes, as assessed with Factor Four of the AAFQ, as important because their subordinates may judge the AA outcomes as unfair practices. Managers' high mean scores probably reflect their sensitivity to and concern about the negative impact of the AA outcomes on non-targeted subordinates' attitudes and work commitment.

Two general conclusions can be drawn from this research. The first of these conclusions deals with differences between those who are or are not members of AA designated groups. Results suggest that employees from target groups perceived the fairness of AA practices as less important than those from a non-targeted group do. This trend is clear for ethnicity, but less clear for gender. The finding is consistent with the results of several studies (Anderson, 2003; Resendez, 2002; Konrad \& Spitz, 2003; Elizondo \& Crozby, 2004), which suggests that ingroupoutgroup differences or self-interest are important moderators of fairness judgements of AA.

The second of these conclusions deals with differences between those who make decisions about or administer AA versus those who do not. The results indicated that managers might have different reasons to perceive the fairness of AA practices as more important than clerical employees do. Overall, it seems that those who are responsible for the management and administration of AA programmes place a higher premium on the fair and just implementation of AA practices than non-decision makers do. Research by Elkins et al. (2003), Greenberg (1988) and Ployhart, Ryan and Bennet (1999) has indicted that managers are deeply concerned that organisational decisions across HR functions appear fair to employees. It has been reported that managers use explanations (social accounts) to manage fairness impressions 'to the extent that ... they may be seen themselves as fairer managers' (Gilliland \& Paddock, 2005:170).

\section{Limitations and needed research}

Overall, the results suggest that the measures of distributive, procedural and interact ional justice are sufficiently reliable and valid to capture the perceived fairness of AA programmes. However, the elements that influence overall perceptions of fairness may depend on the type of organisation, leadership style, and so on. This is based on concerns expressed, for example, by Greenberg (1987) and Ambrose and Kulik (2001) about the context sensitivity of justice perceptions. Researchers should thus endeavour to select measures that incorporate elements that are relevant to specific contexts, and be cautious in generalising the results of AA fairness research across organisational contexts. Not limiting the sample to a single organisation could solve some of the problems related to the context sensitivity of perceptions of AA. The applicability of the four dimensions of the AAFQ must be evaluated across different sample populations as part of further cross-validation. Future studies with the AAFQ are necessary to confirm the external validity of the present study and support the transfer of 
findings to other populations. The promising psychometric properties of the AAFQ should encourage other researchers actively to explore the validity of the four factors that were obtained.

Another limitation concerns the interpretation of Section B of the questionnaire. Respondents were asked to indicate how much certain actions influenced their perceptions of the fairness of AA. Some of the answers provided by respondents gave the impression that they had evaluated the statements according to how AA fairness was dealt with at the institution. It should also be noted that the assumptions underlying the analysis of variance were not completely met. Levene's test of homogeneity of variance indicated that the error variance of the independent variable (interactional justice) was not equal across the sub-groups for ethnicity and staff category respectively. The results of the present study should therefore be validated on a representative sample to examine the true relationship between the justice factors and the biographical variables. In addition, researchers can explore the relationship between independent variables such as personality, moral reasoning, emotional intelligence and organisational citizenship and the factors that constitute fair and just AA practices. This could add value to our understanding of the dynamics of employees' perceptions of organisational justice.

Despite its limitations, the study has made a promising contribution towards working for a better understanding of the dimensionality of AA fairness and it will ultimately help to enhance effective management of AA in the workplace.

\section{References}

Adler, N. 1994. 'Competitive frontiers: Women managing across borders', Journal of Management Development, 13(2):24-41.

Ambrose, M.L. \& Kulik, C.T. 2001. 'How do I know what's fair? A categorization approach to fairness judgments'. In Gilliland, S.W., Steiner, D.D. \& Skarlicki, D.P. (Eds.). Theoretical and cultural perspectives on organizational justice. Greenwich, CT: Information Age Publishing, p.p. 35-62.

Anderson, C. L. 2003. 'Support for race-based affirmative action: Self-interest and procedural justice', Journal of Applied Social Psychology, 33(6):1212-1225.

Bendix, S. 2001. Industrial relations in South Africa. $4^{\text {th }}$ Edition. Lansdowne: Juta.

Brockner, J. \& Wiesenfeld, B.M. 1996. 'An integrative framework for explaining reactions to decisions: Interactive effects of outcomes and procedures', Psychological Bulletin, 120: 189-208.

Clayton, S. D. \& Tangri, S. S. 1989. 'The justice of affirmative action'. In Blanchard F.A . \& Crosby F.J. (Eds.). Affirmative action in perspective. New York: Springer, p.p. 177-192.
Cohen, J. 1988. Statistical power analysis for behavioral sciences. $\left(2^{\text {nd }}\right.$ Edition. Hillsdale, NJ: Lawrence Erlbaum.

Colquitt, J.A. 2001. 'On the dimensionality of organizational justice: A construct validation of a measure', Journal of Applied Psychology, 86:386-400.

Cooper, D. \& Robertson, I.T. 1995. The psychology of personnel selection. London: Routledge.

Cowherd, D.M. \& Levine, D.I. 1992. 'Product quality and pay equity between lower-level employees and top management: an investigation of distributive justice theory', Administrative Science Quarterly, 37:302-320.

Deaux, K. 1976. The behavior of men and women. Monterey, CA: Brooks Cole.

De Jong, A. \& Visser, D. 2000a. 'Organisational justice rules as determinants of black and white employees' fairness perceptions of personnel selection techniques', South African Journal of Industrial Psychology, 26(1):29-38.

De Jong, A. \& Visser, D. 2000b. 'Black and White employees' fairness perceptions of personnel selection techniques', South African Journal of Psychology, 30(4):17-24.

Deutsch, M. 1985. Distributive justice: A social psychological perspective. New Haven, CT: Yale University Press.

Elizondo, E. \& Crozby, F. 2004. 'Attitudes toward affirmative action as a function of strength of ethnic identity among Latino college students', Journal of Applied Social Psychology, 34(9):1773-1796.

Elkins, T.J., Bozeman, D. P. \& Phillips, J. S. 2003. 'Promotion decisions in an affirmative action environment: Can social accounts change fairness perceptions', Journal of Applied Social Psychology, 33(6):1111-1139.

Employment Equity Report. 2001. Pretoria: Department of Labour.

Folger, R. \& Cropanzano, R. 1998. Organizational justice and human resource management. Thousand Oaks, CA: Sage.

Gilliland, S. W. \& Paddock, L. 2005. 'Organizational justice across human resource management decisions'. In Hodgkinson, P. G. \& Ford, J.K. (Eds.). International Review of Industrial and Organizational Psychology. 20:148-175.

Greenberg, J. 1987. 'Reactions to procedural injustice in payment distributions: Do the means justify the ends?' Journal of Applied Psychology, 72:55-61.

Greenberg, J. 1988. 'Equity and workplace status: A field experiment', Journal of Applied Psychology, 73:606-613. 
Greenberg, J. 1990. 'Organizational justice: yesterday, today, and tomorrow', Journal of Management, 16(2):399432.

Greenberg, J. 1996. The quest for justice on the job: essays and experiments. London: Sage.

Groarke, L. 1990. 'Affirmative action as a form of restitution’, Journal of Business Ethics, 9:207-213.

Hair, J.F., Anderson, R.E., Tatham, R.L. \& Black, W.C. 1998. Multivariate data analysis. Englewood Cliffs, NJ: Prentice-Hall.

Harris, L. 2000. 'Procedural justice and perceptions of fairness in selection practice', International Journal of Selection and Assessment, 8(3):148-157.

Hemingway, M.A. \& Conte, J.M. 2003. 'The perceived fairness of layoff practices', Journal of Applied Social Psychology, 33(8):1588-1617.

Janse van Rensburg, K. \& Roodt, G. 2005. 'The perceptions of employment equity and black economic empowerment as predictors of union commitment', South African Journal of Industrial Psychology, 31(1):55-64.

Joy, V.L \& Witt, L.A. 1992. 'Delay of gratification as a moderator of the procedural justice - distributive justice relationship', Group and Organizational Management, 17(3):297-308.

Kaufman, H.G. 1982. Professionals in search of work: coping with the stress of job loss and unemployment. New York: Wiley.

Konovsky, M.A. \& Brockner, J. 1993. 'Managing victim and survivor layoff reactions: a procedural justice perspective'. In Cropanzano, R. (Ed.). Justice in the workplace: Approaching fairness in human resource management. Hillsdale, N J: Lawrence Erlbaum, p.p.133153.

Konrad, A. M. \& Spitz, J. 2003. 'Explaining demographic group differences in affirmative action attitudes', Journal of Applied Social Psychology, 33(8):1618-1642.

Krafft, P., Engelbrecht, A.S. \& Theron, C.C. 2004. 'The influence of transformational and transactional leadership on dyadic trust relationships through perceptions of fairness", South African Journal of Industrial Psychology, 30(1):1018.

Leventhal, G.S. 1976. 'Fairness in social relationships'. In Thibaut, J.W., Spence, J.T. \& Carson, R.C. (Eds.). Contemporary topics in social psychology. Morristown, NJ: General Learning Press, p.p. 211-240.

Leventhal, G.S., Karuza, J. \& Fry, W.R. 1980. 'Beyond fairness: A theory of allocation preferences'. In Mikula, G. (Ed.). Justice and social interaction. New York: Springer, p.p. 167-218.
Morgan, A.G. \& Griego, O.V. 1998. Easy use and interpretation of SPSS for Windows: answering research questions with statistics. London: Lawrence Erlbaum.

Petkoon, L. \& Roodt, G. 2004. 'The discriminant validity of the culture assessment instrument: A comparison of company sub-cultures', South African Journal of Industrial Psychology, 30(1):46-54.

Pfeffer, J. \& Langton, N. 1993. 'The effects of wage dispersion on satisfaction, productivity, and working collaboratively: evidence from college and university faculty', Administrative Science Quarterly, 38(3):382-407.

Ployhart, R.E., Ryan, A.M. \& Bennet, M. 1999. 'Explanations for selection decisions: Applicants' relations to informational and sensitivity features of explanations', Journal of Applied Psychology, 84:87-106.

Resendez, M.G. 2002. 'The stigmatizing effects of affirmative action: an examination of moderating variables', Journal of Applied Social Psychology, 32(1):185-206.

Rosenthal, R., Rosnow, R.L. \& Rubin, D.B. 2000. Contrasts and effect size in behavioural research. Cambridge: Cambridge University Press.

Schepers, J.M. 1992. Toetskonstruksie: Teorie en praktyk. Johannesburg: RAU Press.

Sheppard, B.H., Lewicki, R.J. \& Minion, J.W. 1992. Organisational justice. The search for fairness in the workplace. New York: Lexington.

SIOP. 1996. Affirmative action: A review of the psychological and behavioural research.

[online] URL: http://www.siop.org/siopinfo.html .

Swim, J.K. \& Miller, D.L. 1996. 'White guilt; its antecedents and consequences for attitudes toward affirmative action', Personality and Social Psychology Bulletin, 4: 500-514.

Tabachnick, B.G. \& Fidell, C.S. 2001. Using multivariate statistics. $4^{\text {th }}$ Edition. Boston: Allyn and Bacon.

Tata, J. 2000. 'Influence of role and gender on the use of distributive versus procedural justice principles', Journal of Psychology, 134(3):261-269.

Thibaut, J. \& Walker, L. 1975. Procedural justice: A psychological analysis. Hillsdale, NY: Lawrence Erlbaum.

Thomas, A. 2002. 'Employment equity in South Africa: lessons from the global school', International Journal of Manpower, 23(3):237-255.

Tyler, T.R. 1989. 'The psychology of procedural justice: A test of the group-value model', Journal of Personality and Social Psychology, 57:830-838. 
Van Jaarsveld, I.L. 2000. 'Affirmative action: a comparison between South Africa and the United States', Managerial Law, 42(6):1-48.

Van Niekerk, A. 1996. 'Discrimination in selection and recruitment. An applicant's right to equality of treatment', Contemporary Labour Law, 4(10):105-112.

Van Wyk, M.W. 2002. 'Conceptions of equality and social justice: a philosophical overview with reference to South Africa', Southern African Business Review, 6(2):42-51.

Vermeulen, L.P. 2005. 'Perceptions of procedural justice in the retrenchment of managers', South African Journal of Industrial Psychology, 31(2):40-48.

Visser, D. \& De Jong, A. 2001. 'Comparing fairness perceptions of personnel selection techniques of American, French and South African job applicants', South African Journal of Industrial Psychology, 27(2):62-68.

Watson, M.B. \& Allen, M.M. 1989. 'Work-role salience: Comparison of students in career directed and general degree courses', Psychological Report, 64: 699-704.

Zohar, D. 1995. 'The justice perspective of job stress', Journal of Organizational Behavior, 16(4):487-495. 


\section{APPENDIX A}

\begin{tabular}{|c|c|}
\hline Factor & Questionnaire items \\
\hline 1 & Recognising the value that affirmative action employees bring to the organisation. \\
\hline 1 & Acknowledging that employees from designated groups are capable of performing difficult tasks. \\
\hline 1 & Guiding employees from designated groups in having realistic career expectations. \\
\hline 1 & Informing employees about the affirmative action/employment equity policy, objectives and targets. \\
\hline 1 & Training supervisors to manage a diverse workforce. \\
\hline 1 & Accommodating affirmative action employees’ culture and traditions when organising social events. \\
\hline 1 & $\begin{array}{l}\text { Making accurate and complete records available in respect of appointments, promotions, transfers, performance appraisals, } \\
\text { disciplinary hearings etc. }\end{array}$ \\
\hline 1 & Informing employees about the implications of affirmative action for their career plans. \\
\hline 2 & Regarding all employees’ career advancement as equally important. \\
\hline 2 & Enabling employees to appeal when they feel that they have been discriminated against because of affirmative action. \\
\hline 2 & Giving all applicants an equal chance for influencing the selection decision. \\
\hline 2 & Joint decision-making by all interested parties. \\
\hline 2 & $\begin{array}{l}\text { Providing mechanisms such as suggestion boxes, grievance and disciplinary procedures policies to protect employees } \\
\text { sufficiently against any unfair or discriminatory treatment. }\end{array}$ \\
\hline 2 & Applying procedures and rules strictly and consistently to all employees. \\
\hline 2 & $\begin{array}{l}\text { Adjusting current traditions, systems and practices so that employees from designated groups can be integrated } \\
\text { successfully. }\end{array}$ \\
\hline 3 & Applying selection criteria consistently to all applicants. \\
\hline 3 & Using accurate performance data to evaluate employees’ performance. \\
\hline 3 & Using the same performance standards for all employees. \\
\hline 3 & Using predetermined, job-related selection criteria to make selection decisions. \\
\hline 3 & Using more than one appraiser when evaluating an employee’s performance. \\
\hline 3 & Applying disciplinary action strictly and consistently to all employees. \\
\hline 4 & Giving black managers token positions. \\
\hline 4 & Training employees from designated groups to replace current job incumbents. \\
\hline 4 & $\begin{array}{l}\text { Paying unrealistically high salaries to employees from designated groups in managerial positions in order to meet } \\
\text { employment equity targets. }\end{array}$ \\
\hline 4 & Appointing/promoting less qualified people from designated groups for employment equity purposes. \\
\hline 4 & Targeting people from designated groups to apply for a job by means of employment equity provisions in advertisements. \\
\hline 4 & Using an affirmative action plan and the profile of the current workforce when appointing personnel. \\
\hline 4 & Focusing on the development and advancement of employees from designated groups. \\
\hline 4 & Using criteria such as ethnicity, disability and gender when making appointment decisions. \\
\hline
\end{tabular}

